\title{
Colo-rectal anastomosis with a suturing apparatus in resection of the rectum and colon
}

\author{
A. N. RYGICK, G. M. JUCHVIDOVA, V. L. RIVKIN, CH. F. GUREEVA, \\ AND JU. M. MILITAREV
}

From the Proctological Department, Hospital 67, Moscow, U.S.S.R.

In recent years Soviet and other surgeons have used radical operations (but preserving the sphincter) in patients with cancer of the rectum, low level 'anterior' resection of the rectum giving the best functional results. As it is described in the literature this operation is not less radical than extirpation of the rectum, but sometimes there are great technical difficulties in making an end-to-end anastomosis in the pelvic cavity, resulting in frequent post-operative complications. The frequency of faecal fistula after anterior resection rises from 8 to $13.6 \%$. Consequently in a desire to improve operative technique and to achieve a good anastomosis, instruments have been developed. So far such instruments and techniques in using them have not given good anastomoses.
THE APPARATUS AND MODE OF OPERATION

In the U.S.S.R. mechanical suturing in surgery of the digestive tract has been successful (Gritsman, 1961; Kalinina, 1963) and several workers from the Institute 'BHUUXAU' designed a suturing apparatus for colorectal anastomosis (Kalinina, Babkin, Kasulin, and Gambashidse, 1962-1964). The apparatus KC-28 (Fig. 1), a modification of the apparatus described in the literature as PKS-25, provides for one-stage suturing of two ends of intestine with a circular mechanical (tantalum) suture with the help of a cylindrical knife, the anastomosis fold being directed to the lumen of the intestine. The results in more than 100 experiments on cadavers and dogs showed the anastomosis to be sound and watertight with the mechanical suture, the wound healing with less inflammation than if it had been sutured by hand.

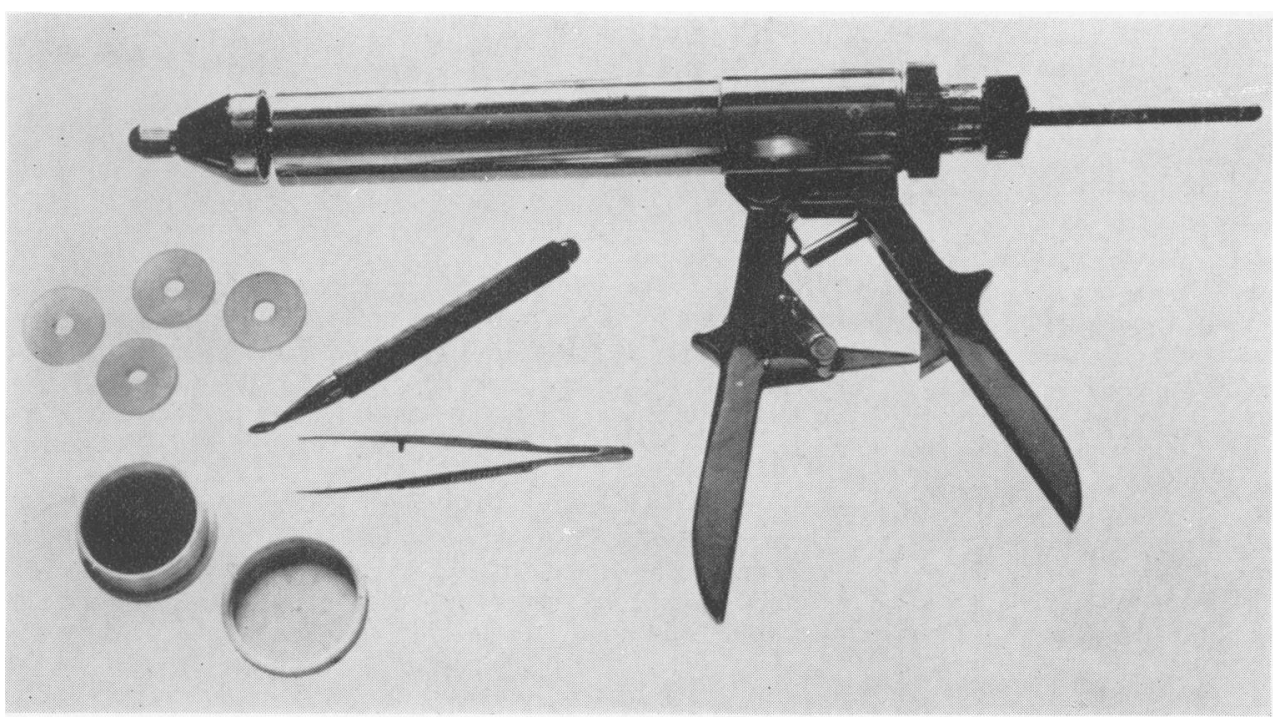

FIG. 1. The apparatus KC-28. 


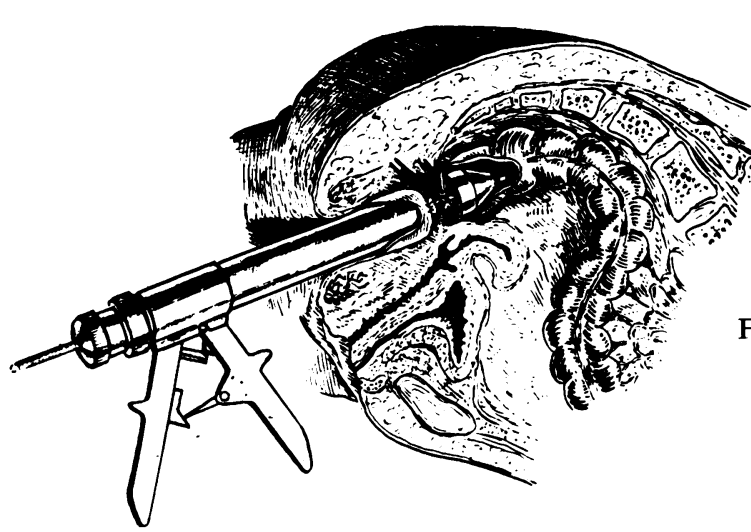

FIG. 2.

In our laboratory the modified apparatus $\mathrm{KC}-28$ was used on 60 patients. Of these, 42 patients had high ampullary or rectosigmoidal cancer of the rectum, most of the tumours being situated $7-8 \mathrm{~cm}$. to $15 \mathrm{~cm}$. from the anus. The patients were from 15 to 73 years old, twothirds being women. All these patients had an anterior resection of the rectum, with end-to-end anastomosis effected by the KC-28. Eight of the patients had extended operations, namely, extirpation of the uterus with uterine appendages, resection of the urinary bladder, small intestine, and so on.

During this operation the patient is put on his back and his buttocks are at the end of the table, the leg part of the table being removed. The patient's legs are abducted and a little bent at the pelvic and knee joints. The apparatus is introduced through the anus (Fig. 2) and the ends of the resected intestine are fixed on to the suturing parts of the apparatus with the silk pouch sutures. The details of the technique are shown in Figure 3. After the ends of the intestine have been fixed on to the apparatus they are drawn together by rotating the screw of the teiling part of the apparatus, and then sutured by pressing the movable handle of the apparatus. The cylindrical knife cuts out the folded pouch ends of the opposed intestine and the anastomosis is made. Anastomosed ends of the intestine after suturing come into contact with their external sero-muscular membrane; the mucosal layer are in the lumen of the intestine. A second layer of silk, hand-knotted sutures around the whole circumference of the anastomosis is made after the apparatus is withdrawn from the rectum and then peritonization is done above the anastomosis. In several cases of a very low anastomosis, at a level $4 \cdot 5-5 \mathrm{~cm}$. from the anus, when it was impossible to make the second row of sutures, we drained the pararectal and presacral space by means of an aperture in the side of the perineum. A large rubber tube with side holes was introduced through the anus and passed $15-20 \mathrm{~cm}$. above the anastomosis. The tube is withdrawn after three to four days.

A caecostomia is not as a rule made.
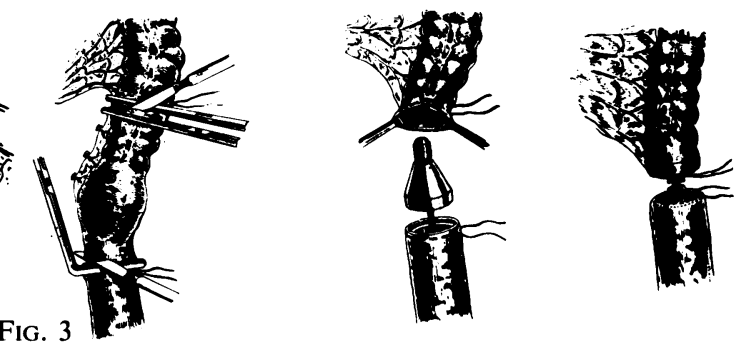

FIG. 2. Introducing the apparatus through the anus.

FIG. 3. Details of the technique for end-to-end anastomosis.

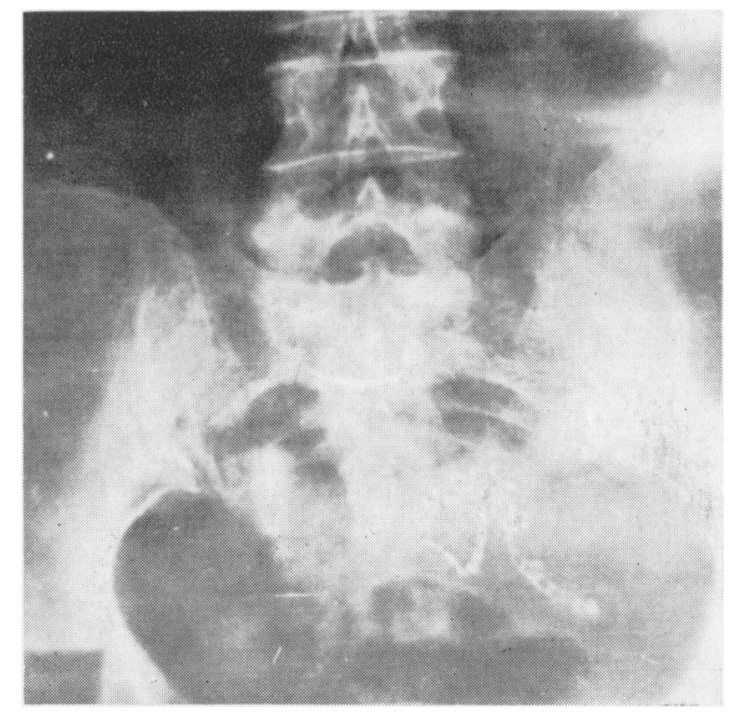

FIG. 4. Radiograph of the patient with diffuse polyposis two months after the ileorectal anastomosis. The end of the sigmoid colon has been sutured with apparatus KC-28.

After the operation three patients had faecal fistulas, two of them closing spontaneously during the two weeks after the operation. The third patient had a transverse stoma made. One patient, aged 61 , died on the 70th day after the operation of necrotic paraproctitis caused by the anastomosis breaking down and purulent pancreatitis resulting.

Ten patients were followed up two years after operation. All are well and the anastomosis has not narrowed.

The apparatus KC-28 can be used not only for colo-rectal but also for ileorectal anastomosis. End-to-end, end-to-side, and side-to-end anastomoses were made in 18 patients with diffuse polyposis of the colon and rectum and non-specific ulcerative colitis. The 
apparatus can be introduced through the anus and through the lumen of the sigmoid colon and ileum from the abdominal cavity. All these patients feel well. They defaecate two to four times a day as before the operation. On radiological examination after operation motor function was normal and narrowing of the anastomosis was not observed (Fig. 4).

With the help of this apparatus anastomosis in the depth of the pelvic cavity becomes easier, and the intestinal wall can be divided much lower than the cancer, thus extending the indications for resection of the rectum but preserving the sphincter. The duration of the operation is shorter and it causes less trauma.

\section{CONCLUSIONS}

With apparatus $\mathrm{KC}-28$ colo-rectal and ileorectal anastomoses can be made successfully. This apparatus shortens low anterior resection of the rectum by 20 to 25 minutes. With the apparatus the operation can be used when the tumour is $7 \mathrm{~cm}$. from the anus in women and 8 to $9 \mathrm{~cm}$. in men.

\section{REFERENCES}

Gritsman, Y. Y. (1961). Tantalovyi Mekhanicheskii Shov pri Rezektsiiakh Zheludka. [Tantalum mechanical suture in gastric resection.] Medgi, Moscow.

Kalinina, T. V., and Kasulin, V. S. (1965). Some aspects of methods of using apparatus PKS-60 and KC-28 in surgery. Scientific Papers, 5th session, Sci. Res. Inst. Surg. appl. Instrum., Moscow.

Gureeva, Kh. Th., Rivkin, V. L., and Kalinina, T. V. (1965). Colorectal and ileorectal anastomoses in cancer and polyposis of colon and rectum. Report on the first meeting of the Russian National Conference of Proctologists, Moscow.

Brumelkamp, R. (1965). The rectoresector: a new instrument for resection of the rectum and colorectal anastomosis without sutures. Dis. Colon Rect., 8, 49-51.

Ravitch, M. M., and Rivarola, A. (1966). Enteroanastomosis with an automatic instrument. Surgery, 59, 270-277.

\section{CORRECTION}

In figures 1 and 2 in the paper by Vibeke Binder and Eigill Hvidberg, entitled 'Histamine content of rectal mucosa in ulcerative colitis' (Gut, 1967, 7, 24) these are two misprints. In Figure 1 the mean value for the histamine content in moderate ulcerative colitis should read 79.1 ; in Fig. 2 the mean value in control subjects should read $71 \cdot 4$. 